\title{
Coronary bypass surgery improves global and regional left ventricular function following thrombolytic therapy for acute myocardial infarction
}

\begin{abstract}
Coronary bypass surgery was performed prior to hospital discharge in $303(22 \%)$ of 1387 consecutive patients enrolled in the TAMI 1 to 3 and 5 trials of intravenous thrombolytic therapy for acute myocardlal infarction. Bypass surgery was of emergency nature ( $<24$ hours from treatment with intravenous thrombolytic therapy) in $36(2.6 \%)$ and was deferred (>24 hours) in $267(19.3 \%)$ patients. The indications for bypass surgery included falled angloplasty (12\%); left main or equivalent coronary disease $(9 \%)$; complex or multivessel coronary disease $(62 \%)$; recurrent postinfarction angina (13\%); and refractory pump dysfunction, mitral regurgitation, ventricular septal rupture or abnormal predischarge functional test ( $1 \%$ each). Although patients having bypass surgery were older (59.5 \pm 9.8 versus $56.0 \pm 10.2$ years, $(p<0.0001)$, had more extensive coronary artery disease ( $46 \%$ with three-vessel disease versus $11 \%$, $(p<0.0001)$, had more frequent diabetes mellitus $(19 \%$ versus $15 \%,(p=0.048)$, had more prior infarctions $(p<0.0001)$, had more severe inltial depression in global left ventricular ejection fraction $(48.0 \pm 11.9 \%$ versus $51.8 \pm 11.9 \%, p=0.0002)$, and regional infarct zone $(-2.7 \pm 0.94$ versus $-2.5 \pm 1.1 \mathrm{SD} /$ chord, $p=0.02)$ and noninfarct zone function $(-0.36 \pm 1.8$ versus $0.43 \pm 1.6$ $\mathrm{SD} /$ chord, $p<0.0001$ ) than patients not having coronary bypass surgery, no difference in the incidence of death in hospital (7\% surgical versus $6 \%$ nonsurgical) or death at long-term follow-up of hospital survivors (7\% surgical versus $6 \%$ nonsurgical) was noted between groups. Surgical patients demonstrated a greater degree of recovery in left ventricular ejection fraction (3.4 $\pm 9.8 \%$ versus $0.16 \pm 8.5 \%, p=0.036)$ and Infarct zone regional function $(0.71 \pm 1.1$ versus $0.34 \pm 0.99 \mathrm{SD} /$ chord, $p=0.001$ ) when immediate (90 minutes following initiation of thrombolytic therapy) and predischarge ( 7 to 14 days after treatment) contrast left ventriculograms were compared than did patients who received only intravenous thrombolytic therapy with or without coronary angioplasty. These data suggest a beneficial influence of coronary bypass surgery on left ventricular function and possibly on the cilnical outcome of patients initially treated with intravenous thrombolytic therapy for acute myocardial infarction (AM HEART J 1991;122:390.)
\end{abstract}

Dean J. Kereiakes, MD, ${ }^{a}$ Robert M. Califf, MD, ${ }^{b}$ Barry S. George, MD, ${ }^{c}$ Stephen Ellis, MD, ${ }^{d}$ Joseph Samaha, MD, ${ }^{\mathrm{e}}$ Richard Stack, MD, ${ }^{\mathrm{b}}$

Linda H. Martin, RN, BSN, MBA, ${ }^{a}$ Sharon Young, MS, ${ }^{b}$ Eric J. Topol, MD, ${ }^{d}$ and the TAMI Study Group.* Cincinnati and Columbus, Ohio; Durham, N.C.; Ann Arbor, Mich.; and Memphis, Tenn.

From ${ }^{a}$ The Christ Hospital Cardiovascular Research Center, Cincinnati; ${ }^{b}$ Division of Cardiology, Duke University, Durham; 'Riverside Methodist Hospital, Columbus; dDepartment of Internal Medicine, Division of Cardiology, University of Michigan, Ann Arbor; and 'Division of Cardiology, Baptist Hospital, Memphis.

Supported in part by research grants from Genentech, Inc., and Abbott Laboratories, Inc.

Received for publication Dec. 11, 1990; accepted Jan. 25, 1991.

Reprint requests: Dean J. Kereiakes, MD, 2123 Auburn Ave., Suite No. 139, Cincinnati, OH 45219.

*Coinvestigators of the TAMI Study Group have been noted previously (Circulation 1989;79:281-6).

4/1/30753
Coronary bypass surgery has served both primary ${ }^{1-5}$ and adjunctive roles 6,7 in strategies directed toward myocardial reperfusion during acute myocardial infarction. Although immediate and long-term results of bypass surgery performed early during the evolution of myocardial infarction have been promising 4,5 practical, logistic, and financial considerations have limited widespread application of this approach. The administration of intravenous thrombolytic therapy early in acute myocardial infarction has been demonstrated to be successful in achieving infarct artery 
reperfusion in a majority of patients and in improving myocardial function as well as reducing hospital and long-term (1 year) mortality following infarction. ${ }^{8-11}$ These salutary effects, in addition to the ease and rapidity of administration, have established intravenous thrombolysis as the standard of care in suitable patients with acute myocardial infarction. However, intravenous thrombolysis fails to achieve infarct artery recanalization in $25 \%$ or more of patients, ${ }^{12}$ and coronary reocclusion following successful thrombolysis may also limit the potential gains to be achieved with this treatment. ${ }^{13}$ Late (greater than 6 hours) coronary thrombolysis or the establishment of myocardial reperfusion by mechanical or surgical methods following failed thrombolysis may also have a long-term beneficial influence by facilitating myocardial healing, reducing infarct expansion, and enhancing electrical stability. ${ }^{14-16}$ These effects may be associated with a reduction in mortality even in the absence of measurable improvements in global and infarct zone regional left ventricular function. ${ }^{14,17}$

We ${ }^{6}$ have previously evaluated the adjunctive role of bypass surgery in a small subset of patients having emergency surgery as part of a sequential reperfusion strategy following thrombolytic therapy for myocardial infarction. In this sequence, bypass surgery was not utilized to initiate myocardial reperfusion but was used instead to maintain reperfusion that had been established by pharmacologic or balloon catheter techniques. The purpose of the present study was (1) to evaluate the immediate and longterm clinical outcomes of patients with and without coronary bypass surgery performed as part of a sequential reperfusion strategy during the initial hospitalization for acute myocardial infarction and (2) to evaluate the influence of coronary bypass surgery on global and regional left ventricular function.

\section{METHODS}

From January 1986 through June 1990, coronary bypass surgery was performed before hospital discharge on 303 $(22 \%)$ of 1387 patients enrolled in the Thrombolysis and Angioplasty in Myocardial Infarction (TAMI) 1 to 3 and 5 trials. Details of study design have been described previously. ${ }^{12,18-21}$ Enrollment criteria included chest pain of less than 6 hours' duration and $\geq 1 \mathrm{~mm}$ ST segment elevation in two or more contiguous electrocardiographic leads. Exclusion criteria included age $>75$ years; history of recent stroke, surgery or trauma; previous history of hemorrhagic disorder; prior coronary bypass surgery; prior $\mathrm{Q}$ wave infarction in the acutely ischemic region; and cardiogenic shock (blood pressure $<85 \mathrm{~mm} \mathrm{Hg}$ unresponsive to volume infusion).

\section{Thrombolytic regimens}

TAMI 1. In the first 178 patients enrolled, the dose of tissue plasminogen activator was $60 \mathrm{mg}$ during the first hour, $20 \mathrm{mg}$ per hour during the second and third hours, and $10 \mathrm{mg}$ for each of the last 5 hours. In the remaining 208 patients, the dose during the first hour was $1.0 \mathrm{mg} / \mathrm{kg}$ of body weight, with a maximum of $90 \mathrm{mg}$; the remaining amount (of a total of $150 \mathrm{mg}$ ) was given in equal amounts per hour over a 5 -hour maintenance infusion. ${ }^{12}$

TAMI 2. Five dose increments of combined tissue plasminogen activator and urokinase were administered in TAMI 2. In groups I and II, $25 \mathrm{mg}$ of tissue plasminogen activator was administered with 0.5 and 1.0 million units of urokinase. In groups 3,4 , and $5,1.0 \mathrm{mg} / \mathrm{kg}$ of tissue plasminogen activator (maximum $90 \mathrm{mg}$ ) with $10 \%$ given as a bolus was administered with $0.5,1.0$, and 2.0 million units of urokinase, respectively. ${ }^{18}$

TAMI $2 A$ (Duke University urokinase protocol). Patients received 3 million units of intravenous urokinase over 45 to 60 minutes. In 42 patients, 1.5 million units of urokinase was given as a bolus followed by 1.5 million units infused over 4.5 to 60 minutes, and in 60 patients 3.0 million units was administered by continuous infusion without a bolus dose. ${ }^{19}$

TAMI 3. Patients received $1.5 \mathrm{mg} / \mathrm{kg}$ tissue plasminogen activator intravenously over 4 hours. The dose was $1.0 \mathrm{mg} /$ $\mathrm{kg}$ over the first hour with $10 \%$ given as a bolus to a maximum first-hour dose of $90 \mathrm{mg}$. Over the next 3 hours, 0.5 $\mathrm{mg} / \mathrm{kg}$ was given, not to exceed a total maintenance infusion of $45 \mathrm{mg}$. Patients were randomly assigned to receive either 10,000 units intravenous heparin or no heparin concurrently. ${ }^{20}$

TAMI 5. Patients were randomly assigned to receive intravenous urokinase, tissue plasminogen activator, or the combination. Urokinase was given as a 1.5 million unit intravenous bolus followed by a 1.5 million unit infusion over 90 minutes. Tissue plasminogen activator was given as 60 $\mathrm{mg}$ in the first hour with $6 \mathrm{mg}$ as a bolus, and a $20 \mathrm{mg}$ infusion each hour for the next 2 hours for a total dose of 100 mg. The combined therapy arm consisted of 1.5 million units of urokinase over 60 minutes with $1 \mathrm{mg} / \mathrm{kg}$ of tissue plasminogen activator, $10 \%$ given as a bolus, and a maximum dose of $90 \mathrm{mg}$ over 60 minutes. Combined thrombolytic therapy was given simultaneously via two separate intravenous lines. ${ }^{21}$

Interventional protocol. Informed consent was obtained from patients prior to their treatment with intravenous thrombolytic therapy. In TAMI 1 to 3 , all patients underwent selective coronary angiography of the infarct-related artery and left ventricular angiography at 90 minutes following the initiation of intravenous thrombolytic therapy. Final infarct-related artery patency was determined after the fourth contrast injection, according to the classification of the Thrombolysis In Myocardial Infarction (TIMI) trial. ${ }^{22}$ Patients with persistent infarct-related artery occlusion (TIMI 0 to 1) and suitable coronary anatomy were offered salvage angioplasty. In TAMI 1, coronary angio- 
Table I. Clinical findings in patients with and without coronary bypass surgery

\begin{tabular}{|c|c|c|c|c|}
\hline & \multicolumn{4}{|c|}{ Type of surgery } \\
\hline & $\begin{array}{c}\text { Emergency } \\
\quad(n=36)\end{array}$ & $\begin{array}{l}\text { Deferred } \\
(n=267)\end{array}$ & $\begin{array}{c}\text { All } \\
(n=303)\end{array}$ & $\begin{array}{c}\text { None } \\
(n=1084)\end{array}$ \\
\hline Age* & $56.4+11.1$ & $60.0 \pm 9.5$ & $59.5+9.8$ & $56.0+10.2$ \\
\hline Male sex & $72 \%$ & $83 \%$ & $82 \%$ & $78 \%$ \\
\hline Diabetest & $22 \%$ & $19 \%$ & $19 \%$ & $15 \%$ \\
\hline Prior infarction $\ddagger$ & $15 \%$ & $25 \%$ & $24 \%$ & $10 \%$ \\
\hline Smoking & $58 \%$ & $78 \%$ & $76 \%$ & $79 \%$ \\
\hline Cardiogenic shock $\$$ & $24 \%$ & $6 \%$ & $8 \%$ & $5 \%$ \\
\hline $\begin{array}{l}\text { Time from chest } \\
\text { pain onset } \\
\text { to thrombolytic } \\
\text { therapy (min) }\end{array}$ & $151.6 \pm 71.0$ & $90.2 \pm 95.5$ & $97.5 \pm 94.9$ & $106.2 \pm 101.0$ \\
\hline $\begin{array}{l}\text { Infarct location } \\
\text { (anterior) } \|\end{array}$ & $61 \%$ & $45 \%$ & $47 \%$ & $42 \%$ \\
\hline
\end{tabular}

plasty was performed for the following indications: (1) patients with suitable coronary anatomy and a $>50 \%$ residual stenosis accompanied by TIMI 2 to 3 flow were randomly assigned to either immediate or deferred ( 7 to 10 days) coronary angioplasty and (2) patients with persistent infarct-related coronary occlusion (TIMI 0 to 1 flow) and suitable coronary anatomy. ${ }^{12}$ Following the experience of TAMI 1, angioplasty was not performed immediately in subsequent trials if TIMI 2 to 3 flow was achieved pharmacologically and was offered only to patients with persistent infarct-related artery occlusion and suitable coronary anatomy. In TAMI 5, patients were randomly assigned to either an "aggressive" catheterization strategy with angiography performed within 90 minutes of initiation of thrombolytic therapy or to a "deferred-elective" procedure with angiography performed at 7 to 10 days following thrombolytic therapy. In the "aggressive" catheterization strategy, if pharmacologic thrombolysis had failed, rescue angioplasty was attempted if the vessel was suitable in the judgment of the investigator. Contraindications to angioplasty included left main stem stenosis in patients with left coronary infarct vessel location or lack of adequate identification of the culprit coronary artery in the setting of multiple vessel occlusion. In the "deferred" cardiac catheterization strategy, patients were eligible for urgent crossover catheterization if recurrent signs or symptoms of myocardial ischemia, hypotension, pulmonary edema, or a new holosystolic murmur were evident.

In the event that angioplasty was unsuccessful in maintaining coronary patency, a coronary perfusion catheter or perfusion balloon catheter was placed over an exchange guide wire and was intermittently flushed with heparinized solution. These catheters were utilized to maintain coronary flow en route to coronary bypass surgery. Not all patients with unsuccessful immediate coronary angioplasty had emergency coronary bypass surgery. Patients were assessed on an individual basis for clinical data suggesting a large, viable, jeopardized myocardial bed or severe multivessel coronary artery disease. The decision to perform emergency coronary bypass surgery was at the discretion of the principal investigator. Surgery was considered an emergency if it was performed within 24 hours of initiation of intravenous thrombolytic therapy and was considered "deferred" if it was performed more than 24 hours following thrombolysis. Patients having complex or severe multivessel coronary artery disease who were thought to be poor candidates for percutaneous transluminal coronary angioplasty were considered for deferred bypass surgery.

Coronary bypass surgery was performed using standard aortic cross-clamping techniques and cold potassium cardioplegia.

Data collection and management. Findings in the trials were collected by the study nurses and were reviewed by the principal investigator at each clinical site. Data for each patient were subjected to a rigorous process of crosschecking with medical record source documentation by trained data monitors. Computer entry and management of study data were performed at the TAMI data coordinating center. All survivors of hospital discharge were followed for at least 1 year or until death. These patients were contacted by telephone and were asked to complete standardized questionnaires regarding general health status, angina status, and return to work.

Statistical analysis. Continuous baseline clinical characteristics of surgically and nonsurgically treated patients were summarized using the mean \pm standard deviation. In instances where the distribution was skewed, the median and selected percentiles were used. Discrete variables were characterized in terms of frequencies and percentages. Statistical comparisons between groups were performed 
Table II. Angiographic findings

\begin{tabular}{|c|c|c|c|c|}
\hline & \multicolumn{4}{|c|}{ Type of surgery } \\
\hline & $\begin{array}{l}\text { Emergency } \\
\quad(n=36)\end{array}$ & $\begin{array}{l}\text { Deferred } \\
(n=267)\end{array}$ & $\begin{array}{c}\text { All } \\
(n=303)\end{array}$ & $\begin{array}{c}\text { None } \\
(n=1084)\end{array}$ \\
\hline \multicolumn{5}{|l|}{ Infarct artery } \\
\hline Left anterior descending & $56 \%$ & $40 \%$ & $42 \%$ & $36 \%$ \\
\hline Left circumflex & $6 \%$ & $11 \%$ & $11 \%$ & $14 \%$ \\
\hline Right coronary & $33 \%$ & $48 \%$ & $46 \%$ & $50 \%$ \\
\hline Left main coronary & $6 \%$ & $0.4 \%$ & 10 & $0 \%$ \\
\hline \multicolumn{5}{|c|}{ Number of diseased vessels ( $>50 \%$ stenosis) } \\
\hline 0 & $0 \%$ & $1 \%$ & $1 \%$ & $7 \%$ \\
\hline 1 & $22 \%$ & $20 \%$ & $20:$ & $56 \%$ \\
\hline 2 & $42 \%$ & $31 \%$ & $33 \%$ & $27 \%$ \\
\hline 3 & $36 \%$ & $47 \%$ & $46 \%$ & $11 \%$ \\
\hline Multivessel disease ( $\geq 2$ vessels) ${ }^{*}$ & $78 \%$ & $78 \%$ & $79 \%$ & $38 \%$ \\
\hline Acute coronary angioplasty $\dagger$ & $39 \%$ & $8 \%$ & $18 \%$ & $32 \%$ \\
\hline
\end{tabular}

${ }^{*} p<0,0001$ all surgery versus none.

$\dagger p<0.0001$ all surgery versus none; $p<0.0001$ emergency versus deferred surgery.

using the Wilcoxon rank sum test in the case of continuous variables and the chi square test in the case of discrete variables. For global and regional measures of left ventricular function, comparisons between groups of the change in function (acute versus predischarge) were performed using linear regression analysis, adjusting the change for the value at the baseline (acute) study. All $p$ values presented are based on two-tailed significance testing.

Analysis of left ventricular function. Outlines of right anterior oblique contrast ventriculograms obtained at 90 minutes following initiation of thrombolytic therapy and prior to hospital discharge were traced manually by an independent observer, who was blinded to patient data at the Core Angiographic Laboratory at the University of Michigan. Left ventricular ejection fraction was determined by the area-length method. ${ }^{23}$ Regional wall motion was determined by the computer-assisted center-line chord method of Bolson et al. ${ }^{24}$ and was expressed as standard deviations (SD) per chord. Representative end-diastolic and end-systolic frames were digitized and stored in the memory of a digital radiographic computer (DPS 4100C, Adac Laboratories, Milpitas, Calif.) for processing. Ventriculograms considered technically inadequate because of ventricular ectopic beats or inadequate opacification were not included in the analysis.

\section{RESULTS}

Coronary bypass surgery was performed on 303 $(22 \%)$ of 1387 consecutive patients enrolled in the TAMI 1 to 3 and 5 trials. Surgery was of emergency nature in $36(2.6 \%)$ and was deferred ( $>24$ hours) in 267 patients $(19.3 \%)$. The clinical features of the surgical patients are compared in Table I with those of the 1084 patients ( $78 \%$ ) who did not have surgery during the initial hospitalization for acute myocardial infarction. As a group, patients having surgery were older $(p<0.0001)$, more often had diabetes
Table III. Indications for bypass surgery

\begin{tabular}{lrrrrr}
\hline & \multicolumn{3}{c}{ Type of surgery } \\
\cline { 2 - 3 } \multicolumn{1}{c}{ Indication } & \multicolumn{2}{c}{ Emergency } & & \multicolumn{2}{c}{ Deferred } \\
\cline { 2 - 3 } \cline { 5 - 6 } & No. & $(\%)$ & No. & $(\%)$ \\
\hline Failed PTCA & 14 & $(39)$ & 21 & $(8)$ \\
Left main/Equivalent disease & 7 & $(19)$ & 21 & $(8)$ \\
Complex coronary anatomy & 11 & $(81)$ & 176 & $(66)$ \\
Recurrent angina & 4 & $(11)$ & 35 & $(13)$ \\
Refractory pump dysfunction & 0 & & 5 & $(2)$ \\
Mitral regurgitation & 0 & & 3 & $(1)$ \\
Ventricular septal rupture & 0 & & 3 & $(1)$ \\
Abnormal functional study & 0 & & 3 & $(1)$
\end{tabular}

PTCA, Percutaneous transluminal coronary angioplasty

mellitus $(p=0.048)$, more often had a prior infarction $(p<0.0001)$, and had more frequent cardiogenic shock early following thrombolytic therapy $(p=$ 0.059 ) than patients who did not undergo surgery.

The distribution of anterior myocardial infarction, infarct-related artery location, and the number of diseased coronary vessels for both groups are shown in Table II. Surgical patients had more extensive multivessel coronary disease ( $p<0.0001$ ) than nonsurgical patients. The clinical indications for surgery are shown in Table III.

Left ventricular function. Analysis of immediate and deferred (prediecharge) global left ventricular ejection fraction as well as change in left ventricular ejection fraction from analyois of paired ventricular studies (adjusted for the immediate left ventricular function value) are shown in Fig. 1. Immediate ventriculograms suitable for analysis were available from 


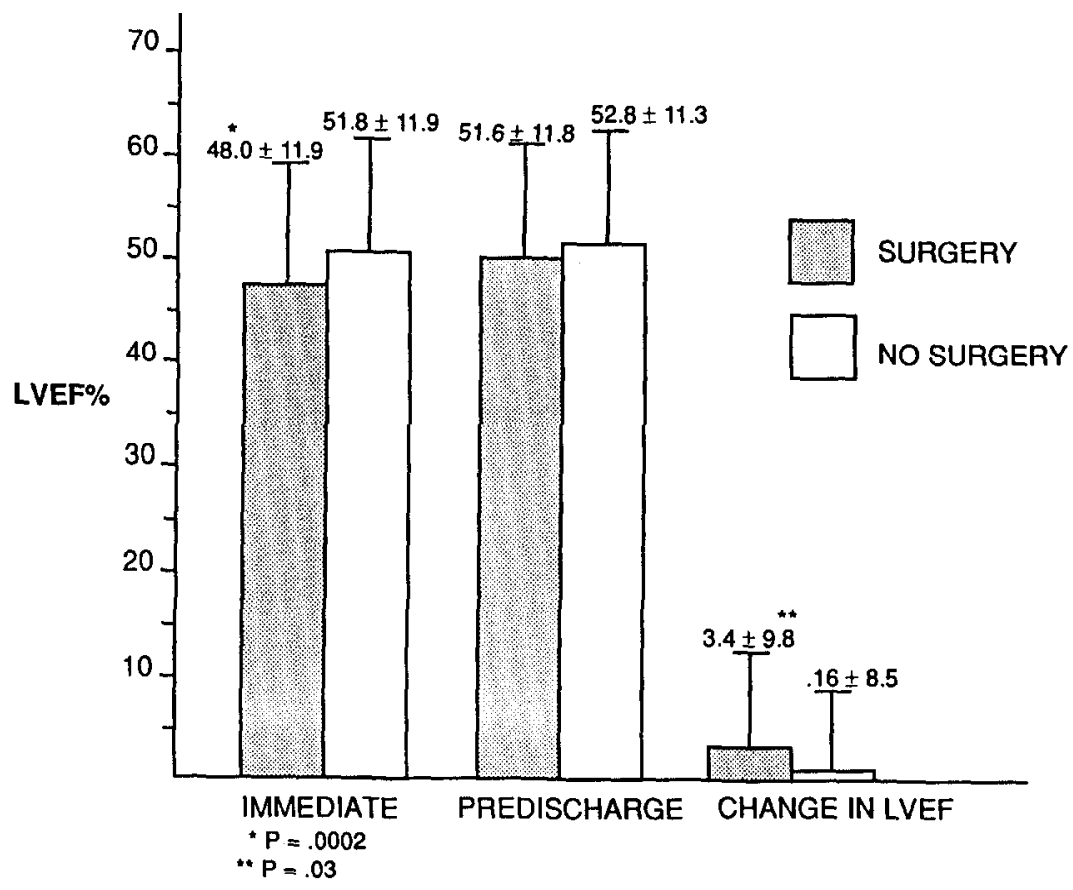

Fig. 1. Immediate and predischarge left ventricular ejection fraction $(L V E F)$ and absolute change in LVEF between paired studies for patients with and without coronary bypass surgery. Surgical patients had more depressed immediate left ventricular function and a greater increment in LVEF before hospital discharge.

193 of $303(64 \%)$ of surgical patients (25 of 36 emergency patients; 168 of 267 deferred patients) and from 720 of $1084(66 \%)$ of nonsurgical patients. Suitable predischarge studies were obtained from 194 of $283(69 \%)$ surgical survivors (17 of 30 emergency patients, 177 of 253 deferred patients) and from 840 of $1020(82 \%)$ of nonsurgical patients. Surgical patients had a greater depression in initial left ventricular ejection fraction $(48.0 \pm 11.9 \%$ versus $51.8 \pm 11.9 \% ; p=0.0002$ ), initial infarct zone $(-2.7 \pm 0.94$ versus $-2.5 \pm 1.1 \mathrm{SD} /$ chord; $p=0.02)$ and noninfarct zone function $(-0.36 \pm 1.8$ versus $0.43 \pm 1.6 \mathrm{SD} /$ chord; $p<0.0001$ ) than nonsurgical patients (Figs. 1 and 2). At predischarge angiographic follow-up, no significant difference in left ventricular ejection fraction $(51.6 \pm 11.8 \%$ versus $52.8 \pm 11.3 \%$; $p=0.20)$ or infarct zone function $(-2.1 \pm 1.3$ versus $-2.3 \pm 1.2 \mathrm{SD} /$ chord; $p=0.12$ ) between surgical and nonsurgical groups were noted. Late angiographic evaluation demonstrated a persistent significant difference in noninfarct zone function between groups $(-0.17 \pm 1.6$ surgical versus $0.35 \pm 1.3 \mathrm{SD} /$ chord for nonsurgical patients; $p<0.0001$ ). After adjustment for initial or immediate values of function, surgical patients demonstrated a greater degree of recovery in global ejection fraction and regional (infarct zone) function than patients not having bypass surgery. The changes in left ventricular ejection fraction in surgical and nonsurgical patients were $3.4 \pm 9.8 \%$ versus $0.16 \pm 8.5 \%(p=0.036)$ and in infarct zone regional function the changes were $0.71 \pm 1.1$ versus $0.34 \pm 0.99 \mathrm{SD} /$ chord $(p=0.001)$, respectively. No statistically significant difference with respect to change in noninfarct zone function was noted between groups $(0.30 \pm 1.3$ surgical versus $-0.17 \pm 1.1$ $\mathrm{SD} /$ chord nonsurgical; $p=0.15$ ).

The results of immediate and predischarge evaluation of left ventricular global and regional function for patients having emergency and deferred bypass surgery are shown in Figs. 3 and 4. Substantial recovery of both global left ventricular ejection fraction and infarct zone regional function was observed for both groups of surgical patients; however, no difference with respect to the degree or extent of functional recovery was noted between groups.

Hospital course. Perioperative hemodynamic support with intravenous inotropic agents was required in $32 \%$ and intraaortic balloon pump counterpulsation was required in $10 \%$ of surgical patients. Despite the need for early hemodynamic support, $97 \%$ of patients survived the operative procedure. In-hospital death occurred with similar frequency in surgical $(6.6 \%)$ and nonsurgical $(5.9 \%)$ patients.

Post hospital follow-up. After a median follow-up of 1092 days in surgical patients and 1099 days in nonsurgical patients, the occurrence of death and recur- 


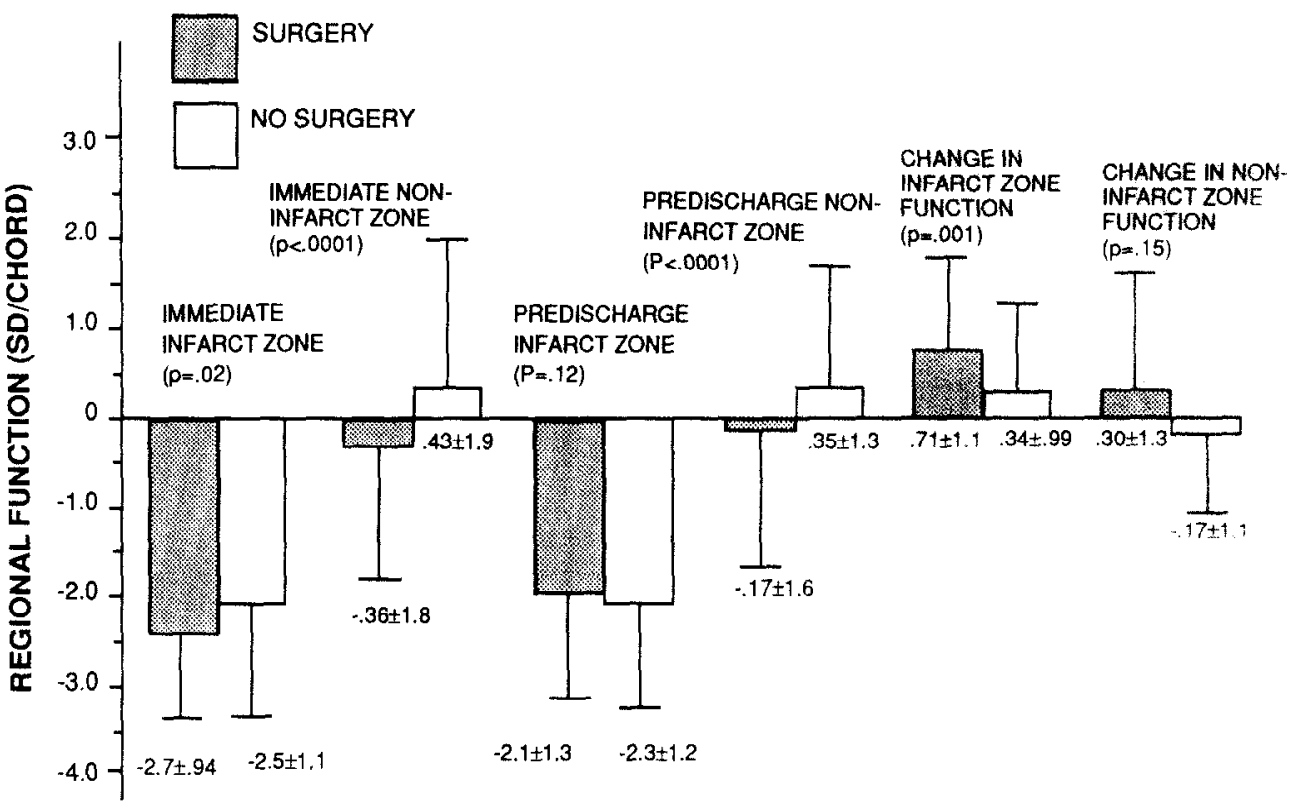

Fig. 2. Immediate and predischarge infarct zone and noninfarct zone regional left ventricular function in patients with and without coronary bypass surgery (see text).

rent nonfatal myocardial infarction was similar in both groups (Table IV). The need for revascularization procedures (bypass surgery and PTCA) was more frequent in patients who did not undergo surgical revascularization during the initial hospitalization (18\% nonsurgical versus $7 \%$ surgical group). Similarly, at a median follow-up of 1251 days for the emergency and 965 days for the deferred surgical groups, the incidence of death (4\% emergency; $8 \%$ deferred) was not different and the need for repeat revascularization procedures was more frequent in patients who had undergone emergency $(20 \%)$ versus deferred $(6 \%)$ surgery (Table IV).

\section{DISCUSSION}

The present study evaluates both clinical outcomes and left ventricular function of patients undergoing coronary bypass surgery as part of a sequential reperfusion strategy for the treatment of acute myocardial infarction and compares these findings with those of patients enrolled into the same multicenter (TAMI) trials of intravenous thrombolytic therapy who did not have bypass surgery performed. Primary surgical reperfusion therapy for myocardial infarction was not evaluated in this study.

Left ventricular function. We have previously reported ${ }^{6}$ that emergency coronary bypass surgery employed in a sequential reperfusion strategy following intravenous thrombolytic therapy for acute myocardial infarction was associated with substantial im- provements in global and regional infarct zone left ventricular function. In this previous trial, as in the current study, surgery was not used to initiate myocardial reperfusion but instead was used to maintain perfusion that had been achieved by pharmacologic or balloon catheter techniques in the vast majority of cases. When employed in this fashion, the timing of surgery (less than 6 hours versus more than 6 hours after infarct symptom onset) did not appear to influence the degree of left ventricular functional recovery. ${ }^{6}$ These results are in contrast to those of prior reports using primary surgical reperfusion therapy for acute myocardial infarction, demonstrating that patients operated $<6$ hours from the onset of symptoms had significantly greater recovery of left ventricular function and improved survival in longterm follow-up. ${ }^{4,5}$

In the present study, surgical patients had more severe depression in left ventricular global function as assessed by immediate contrast ventrieulography (Fig. 1). Comparison of predischarge left ventriculograms demonstrated no significant difference between left ventricular ejection fractions in either group, thus reflecting a greater degree of functional recovery in surgical patients. In addition, more marked recovery of infaret zone left ventricular function was observed in surgical patients, even after adjustment for the more severe depression of infarct zone function observed on early ventriculagraphy in this group (Fig. 2). As noted previously, surgical patients also demonstrated more severe depression in 


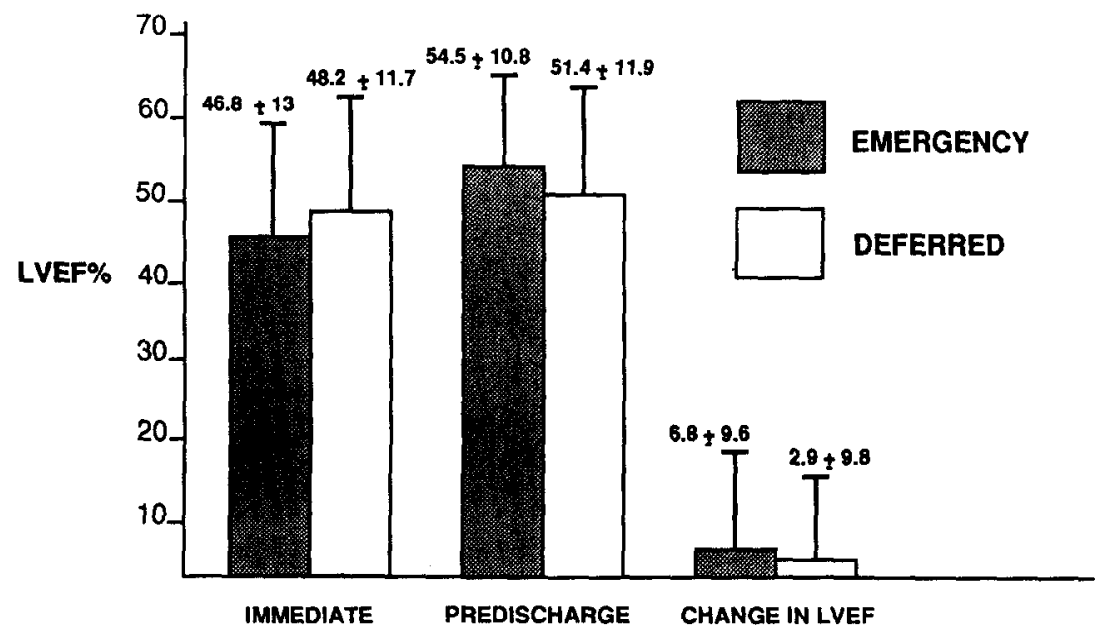

Fig. 3. Immediate and predischarge left ventricular ejection fraction ( $L V E F)$ for patients having emergency and deferred coronary bypass surgery. No significant differences in absolute LVEF or change in LVEF were observed.

Table IV. Events post discharge

\begin{tabular}{lrrrr}
\hline & No CABG & CABG & Emergency CABG & Deferred CABG \\
\hline Death & $6.2 \%$ & $7.2 \%$ & $3.7 \%$ & $7.7 \%$ \\
Nonfatal MI & $8.4 \%$ & $5.3 \%$ & $4.0 \%$ & $5.6 \%$ \\
PTCA & $10.2 \%$ & $4.2 \%$ & $12.0 \%$ & $3.1 \%$ \\
CABG & $7.7 \%$ & $3.2 \%$ & $8.0 \%$ & $2.5 \%$ \\
\hline
\end{tabular}

CABG, Coronary artery bypass graft surgery; MI, myocardial infarction; other abbreviations as in Table III.

noninfarct zone regional left ventricular function than did nonsurgical patients. This finding may in part be explained by the more frequent occurrence of multivessel coronary artery disease in the surgical patients, leading to ischemic dysfunction in left ventricular regions distinct from the acute infarct zone..$^{25}$ Although no significant differences were noted between surgical and nonsurgical patients with respect to predischarge left ventricular ejection fraction and regional infarct zone function as noted above, deferred noninfarct zone left ventricular function remained depressed in surgical patients. Unlike the changes observed for global ejection fraction and regional infarct zone function, no difference in the degree of change in noninfarct zone function was noted between groups. Individual group analysis revealed compensatory hyperfunction of the noninfarct zone on the immediate ventriculogram $(0.43 \pm 1.6 \mathrm{SD} /$ chord) that was persistent at the predischarge evaluation $(0.35 \pm 1.3 \mathrm{SD} /$ chord $)$ in nonsurgical patients. Although some improvement in noninfarct zone function between early and late studies $(-0.36 \pm 1.8$ to $-0.17 \pm 1.6 \mathrm{SD} /$ chord $)$ was observed in surgical patients, no statistically significant difference was noted with respect to the magnitude of change between groups $(0.30 \pm 1.3$ versus $-0.17 \pm$ 1.1, surgical and nonsurgical groups, respectively).

Thus the degree of recovery in both global and regional infarct zone left ventricular function noted in patients who underwent coronary bypass surgery as part of a sequential reperfusion strategy clearly exceeded the degree of functional recovery noted following therapy with intravenous thrombolysis with or without coronary angioplasty. In addition, improvement in global and regional (infarct zone) left ventricular function was observed whether surgery was performed on an emergency or deferred basis, and no differences were noted in the degree of functional recovery between surgical groups.

Although some degree of enhancement in left ventricular function may be attributable to an increase in circulating catecholamines and to other factors following major cardiac surgery, the magnitude of such changes appears small in comparison with the improvement noted in the present series. ${ }^{26,}{ }^{27}$ In addition, any specific improvement in left ventricular function attributable to surgically-induced hormonal changes alone would at least in part be counterbalanced by similar hormonal changes present secondary to the stress of myocardial infarction in the non- 


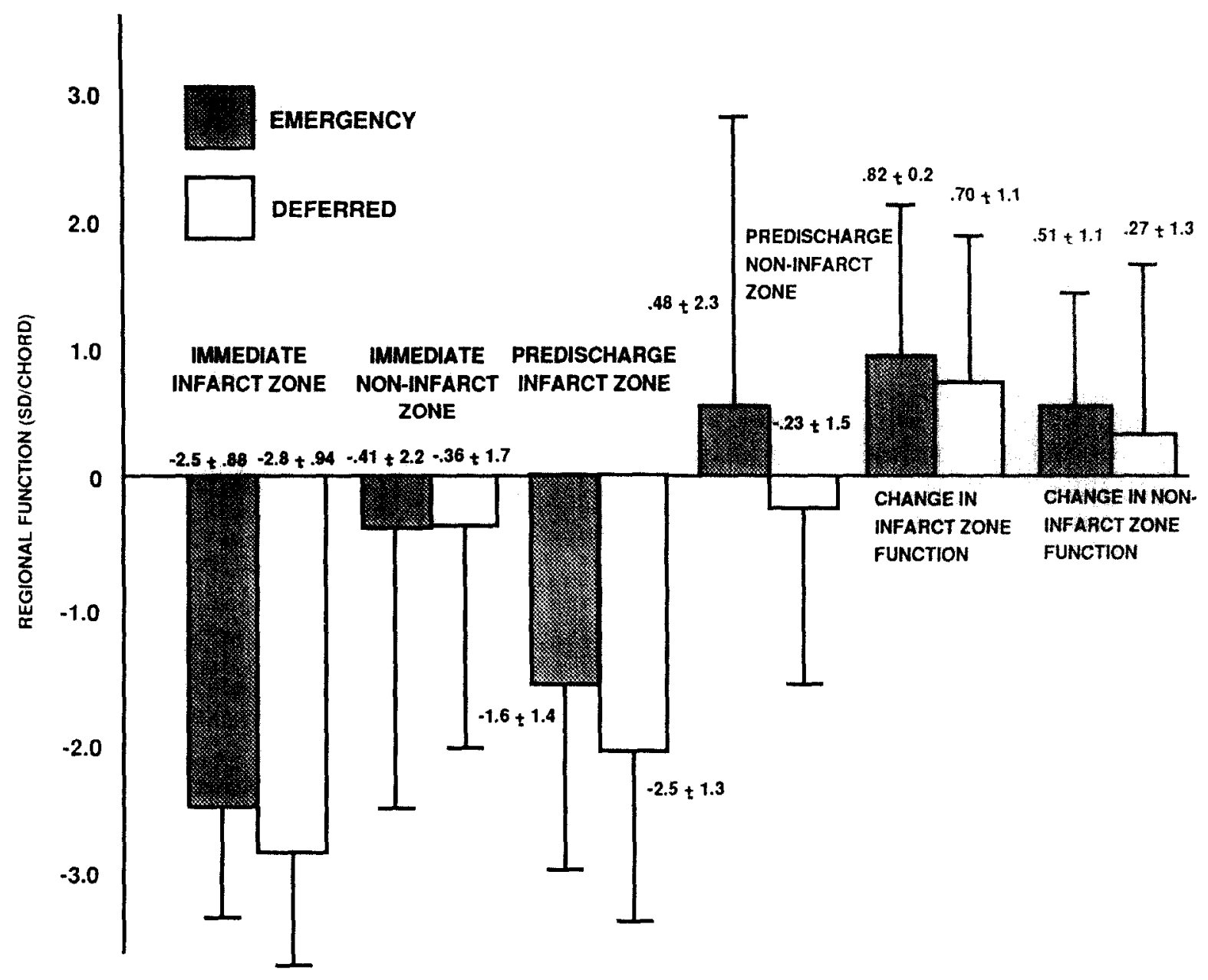

Fig. 4. Immediate and predischarge infarct zone and noninfarct zone regional left ventricular function in patients with emergency and deferred coronary bypass surgery. No significant differences in absolute regional function or change in regional function were observed.

surgical patients. ${ }^{28,}{ }^{29}$ This contention is at least in part substantiated by the observation of persistent hyperfunction of noninfarct zone function noted late following discharge in the nonsurgical group.

A more specific metabolic benefit attributable to surgical coronary revascularization is suggested by these observations. As the vast majority of surgical patients had established myocardial reperfusion preoperatively, the velocity of reperfusion and the composition of initial reperfusate could not be controlled and would not be expected to be different between groups. A cytoprotective or preservative effect of cardioplegia during or soon following the acute infarction process may have enhanced functional recovery. Prior reports have suggested the potential benefit of gradual reperfusion with a reperfusate low in calcium that contains the Krebs cycle intermediates, glutamate and aspartate ${ }^{30}$ Early recovery of regional (infarct zone) left ventricular function following surgical revascularization in patients 8 hours after the onset of acute myocardial infarction has been demonstrated previously using techniques of controlled reperfusion. ${ }^{30}$ These considerations may be most applicable to patients who have severe ischemic left ventricular dysfunction. ${ }^{31}$

Prior reports have demonstrated improvement in left ventricular ejection fraction and regional infarct zone function when primary surgical myocardial reperfusion is performed early (within 6 hours) but not later following infarct symptom onset. ${ }^{4,5} \mathrm{As}$ noted previously, patients in the present surgical series had infarct artery recanalization by pharmacologic or balloon catheter techniques, with surgery performed more than 6 hours from infarct symptom onset in the majority of cases.

Limitations. Although the present study represents 
a large surgical series from which potentially important observations can be made, surgery was performed on a nonrandom basis without a comparable control group for comparison. As the indications for bypass surgery following intravenous thrombolysis were those used in everyday clinical practice, the observations made may have considerable practical application.

Conclusions. This study evaluates clinical outcome and left ventricular function in patients having coronary bypass surgery performed as part of a sequential myocardial perfusion strategy following intravenous thrombolytic therapy during the first hospitalization for acute myocardial infarction. Approximately one of five patients $(22 \%)$ enrolled into the TAMI 1 to 3 and 5 trials had coronary bypass surgery during their initial hospitalization. Despite older age, more extensive multivessel coronary artery disease, more depressed left ventricular function, and more frequent occurrence of diabetes mellitus in patients having surgery, no difference in hospital mortality or incidence of death at long-term followup of hospital survivors was noted between surgical and nonsurgical groups. Patients undergoing bypass surgery experienced greater functional recovery in global left ventricular ejection fraction and infarct zone regional function than did patients treated only with intravenous thrombolytic therapy with or without coronary angioplasty. These data suggest a beneficial role for coronary bypass surgery with respect to recovery of left ventricular function and clinical outcome when this procedure is employed as part of a sequential reperfusion strategy for patients with acute myocardial infarction.

\section{REFERENCES}

1. Athanasuleas CL, Geer DA, Araciniega JG, et al. A reappraisal of surgical intervention for acute myocardial infarction. $J$ Thorac Cardiovasc Surg 1987;93:405-14.

2. Phillips S, Zeff R, Skinner J, et al. Reperfusion protocol and results in 738 patients with evolving myocardial infarction. Ann Thorac Surg 1986;41:119-25.

3. Phillips $\mathrm{S}$. Surgery in evolving acute myocardial infarction. In: Roberts A, Conti CR, eds. Current surgery of the heart. Philadelphia: JB Lippincott Co, 1987:247-56.

4. DeWood MA, Notske RN, Berg R, et al. Medical and surgical management of early $Q$-wave myocardial infarction. I. Effects of surgical reperfusion on survival, recurrent myocardial infarction, sudden death and functional class at 10 or more years of follow-up. J Am Coll Cardiol 1989;14:65-77.

5. DeWood MA, Leonard J, Grunwald RP, et al. Medical and surgical management of early $Q$-wave myocardial infarction. II. Effects on mortality and global and regional left ventricular function at 10 or more years of follow-up. J Am Coll Cardiol 1989;14:78-90.

6. Kereiakes DJ, Topol EJ, George BS, et al. Emergency coronary bypass surgery preserves global and regional left ventric- ular function after intravenous tissue plasminogen activator therapy for acute myocardial infarction. J Am Coll Cardiol 1988;11:899-907.

7. Kereiakes DJ, Topol EJ, George BS, et al. Favorable early and long-term prognosis following coronary bypass surgery therapy for myocardial infarction: results of a multicenter trial. AM HEART J 1989;118:199-207.

8. Gruppo Italiano per lo Studio della Streptokinase nell Infarcto miocardico (GISSI). Effectiveness of intravenous thrombolytic treatment in acute myocardial infarction. Lancet 1986;1:397. 401.

9. Guppo Italiano per lo Studio della Streptokinase nell Infarcto miocardioco (GISSI). Long-term effects of intravenous thrombolysis in acute myocardial infarction: final report of the GISSI study. Lancet 1987;2:871-4.

10. Simoons M, Serruys P, Brand M, et al. Early thrombolysis in acute myocardial infarction: limitation of infarct size in improved survival. J Am Coll Cardiol 1986;7:717-28.

11. Topol EJ, Califf RM, Kereiakes DJ, George BS. Thrombolysis and Angioplasty in Myocardial Infarction (TAMI) trial. . Am Coll Cardiol 1987;10:65B-74B.

12. Topol EJ, Califf RM, George BS, et al. A multicenter randomized trial of intravenous recombinant tissue plasminogen activator in immediate versus deferred angioplasty in acute myocardial infarction. N Engl J Med 1987;317:581-7.

13. Califf RM, Topol EJ, George BS, et al. Characteristics and outcome of patients in whom reperfusion with intravenous tissue type plasminogen activator fails: results of the Thombolysis and Angioplasty in Myocardial Infarction (TAMI) I trial. Circulation 1988;77:1090-9.

14. ISIS-II (Second International Study of Infarct Survival collaborative group). Randomized trial of intravenous streptokinase, or aspirin, both or neither among 17187 cases of suspected myocardial infarction: ISIS-II. Lancet 1988;2:34960.

15. Guerci AD, Gerstenblith G, Brinker JA, et al. A randomized trial of intravenous tissue plasminogen activator for acute myocardial infarction with subsequent randomization to elective coronary angioplasty. N Engl J Med 1987;317:1613-8.

16. Schroder R, Nuhaus KL, Linderer T, Bruggemann T, Tebbe $\mathrm{U}$, Wegscheider $\mathrm{K}$. Impact of late coronary artery reperfusion on left ventricular function one month after acute myocardial infarction (results from the ISAM study). Am $J$ Cardiol 1989;64:878-84.

17. Abbottsmith CW, Topol EJ, George BS, et al. Fate of patients with acute myocardial infarction with successful chemical versus rescue mechanical patency of the infarct vessel. J Am Coll Cardiol 1990;16:770-8.

18. Topol EJ, Califf RM, George BS, et al. Coronary arterial thrombolysis with combined infusion of recombinant tissue plasminogen activator and urokinase in patients with acute myocardial infarction. Circulation 1988;5:1100-7.

19. Wall TC, Phillips H, Stack RS, et al. Results of high dose intravenous urokinase for acute myocardial infarction. Am J Cardiol 1990;65:124-31.

20. Topol EJ, George BS, Kereiakes DJ, et al. A randomized controlled trial of intravenous plasminogen activator and early intravenous heparin in acute myocardial infarction. Circulation 1989;79:281-6.

21. Califf RM, Topol EJ, Stack RS, et al. An evaluation of combination thrombolytic therapy and timing of cardiac catheterization in acute myocardial infarction: results of the TAMI 5 randomized trial. Circulation 1991;83:1543-56.

22. The TIMI study group. The Thrombolysis In Myocardial Infarction (TIMI) trial. N Engl J Med 1985;312:932-6.

23. Dodge H, Sandler H, Baxley W, Hawley R. Usefulness and limitations of radiographic methods for determining left ventricular volume. Am J Cardiol 1966;18:10-24.

24. Bolson E, Kliman S, Sheehan F, Dodge H. Left ventricular se- 
quential wall motion: a new method using local directional information. IEEE Comput Cardiol 1980;1:245-8.

25. Grines CL, Topol EJ, Califf RM, et al. Prognostic implications and predictors of enhanced regional wall motion of the noninfarct zone after thrombolysis and angioplasty therapy of acute myocardial infarction. Circulation 1989;80:245-53.

26. Austin EH, Oldham HN, Sabiston DC, Jones RH. Early assessment of rest and exercise left ventricular function following coronary artery surgery. Ann Thorac Surg 1983; 35:159-69.

27. Floyd RD, Sabiston DC, Lee KL, Jones RH. The effect of duration of hypothermic cardioplegia on ventricular function. $J$ Cardiovasc Surg 1983;85:606-11

28. Ceremuzynski L. Hormonal and metabolic reactions evoked by acute myocardial infarction. Circ Res 1981;48:767-76.
29. Karlsberg RP, Cryer PE, Roberts R. Serial plasma catecholamine response early in the course of clinical acute myocardial infarction: relationship to infarct extent and mortality. AM HEART J 1981;102:24-31.

30. Allen BS, Buckberg GD, Schwaiger M, et al. Studies of controlled reperfusion after ischemia. XVI. Early recovery of regional wall motion in patients following surgical revascularization after eight hours of acute coronary occlusion. $J$ Thorac Cardiovase Surg 1986;92:636-48.

31. Laks H, Rosenkranz E, Buckberg GD. Surgical treatment of cardiogenic shock after myocardial infarction. Circulation 1986;74:II-11-16. 